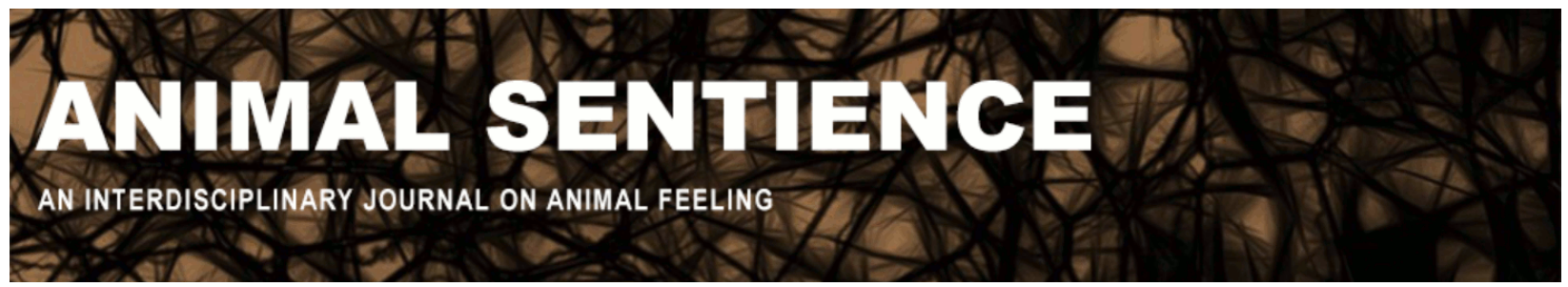

Baker, Liv (2020) Rewilding and mixed-community collaboration in conservation. Animal Sentience 28(21)

DOI: $10.51291 / 2377-7478.1643$

Date of submission: 2020-09-08

Date of acceptance: $2020-10-16$ (c) 


\title{
Rewilding and mixed-community collaboration in conservation
}

Response to Commentary on Baker \& Winkler on Elephant Rewilding

\author{
Liv Baker \\ Animal Behavior and Conservation Program, Hunter College \\ Rebecca Winkler \\ Department of Anthropology, University of Pennsylvania
}

\begin{abstract}
Rewilding is a psychological and sociocultural event for nonhuman animals that goes beyond the traditional framework of ecology. Elephants need to be seen as political agents in a collaboration. Our commentators shed light on the hierarchical assumptions and politics involved. Mixed-community collaboration can create dynamic and sustainable conservation interventions that are crucial to reconceptualizing the human-elephant relationship beyond the concept of labor. The profound effects of the Covid-19 pandemic have laid bare the fundamental vulnerabilities of the elephant tourism industry. Moreover, how well an elephant has been buffered by the fallout of the pandemic is dependent on the specific relations between mahouts and elephants.
\end{abstract}

Keywords: animal welfare; compassionate conservation; covid-19; elephants; multispecies justice; rewilding

Liv Baker, conservation behaviorist and expert in wild animal welfare, explores similar patterns of wellbeing seen across the animal kingdom. Her work includes elephants, arachnids, rodents, pigs. primates, cetaceans, and macropods, Liv teaches at Hunter College, CUNY, and is the research director with Mahouts Elephant Foundation, UK. Website

Rebecca Winkler is a PhD student in the Department of Anthropology at the University of Pennsylvania with interest in animal studies and multidisciplinary environmental justice. Rebecca consults for Mahouts Elephant Foundation on their ongoing projects. Website

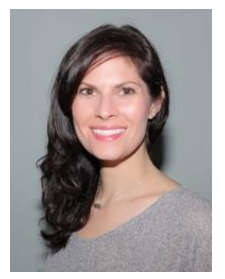

1. On rewilding. We thank the commentators on our target article (Baker \& Winkler, 2020). As some of the commentators note, the idea of rewilding has primarily concerned ecological processes and the status of wilderness areas (Blumstein \& Lynch; Suter). With this conventional wisdom, some commentators question whether our view of rewilding is indeed rewilding (Blumstein \& Lynch). Some also point out that traditional rewilding schemes have not always yielded beneficial outcomes for the individual beings involved (Merkham \& Fas; Suter). In our target article we challenge the myopia of the conventional approach to rewilding, which has historically focused on biotic interactions but neglected the relationships between social beings and their environments. We see rewilding as not just an 
ecological phenomenon, but a psychological one (Pauketat), in which we must recognize elephants as persons (Locke 2017; Wise 2012) actively engaged in forming relationships and creating meaning in their own lives and communities. Rewilding should be a collaboration among members of a mixed community in which (in our case) elephants are enfranchised (see also Treves; Wallach et al.).

Our view does not exclude (ecological) community dynamics; but unlike the way rewilding is usually conceived (e.g., Blumstein \& Lynch), ecological dynamics are just one set of dynamics among many that must be considered. A conventional ecological framework neglects the social and cultural relations among animals. In the case of our own and other proposed rewilding sites in rural northern Thailand, the ecological effects of elephants in these forest fragments are far better known than some commentators realize (Blumstein \& Lynch; Lee \& Lindsay; Massiot; McGrew; Snijders, Phalke). Elephant numbers have been steadily declining for the last 100 years in the wild but most of the removal of elephants from the forests in Thailand for use in the tourism industry has been happening in the last 30 years -- the last 5-10 in the regions we are writing about. Yet certain elephants and mahouts have maintained a connection with their communities, with elephants periodically returning to the associated forests for variable durations.

2. On collaboration and producing and evaluating knowledge. We concur with Laine that more ethnographic work is needed to better understand the particular, situated relations among local human and elephant community members, including in areas where these relations may be to various degrees hostile. We advocate a collaborative effort among communities with different knowledge and practices. This calls for developing deep enough relations among members to be able to engage in good faith to reconcile diverse knowledge, concerns, and needs.

Many commentators were highly critical of the knowledge of indigenous collaborators and the politics of knowledge production (Suter; Treves; Correia-Caeiro, Merkham \& Fas, Kopnina), but this critical thinking did not seem to extend to Westerncentric zoos, academies and institutions. Instead, the assumption seems to have been that modern, "civilized" society is a moralizing force in adjudicating what is uncivilized and amoral (i.e., indigenous or aboriginal) (Mol and Law, 2002). Merkham \& Fas go so far as to

"caution against advocating traditional mahoutship without analyzing their practices... It remains to be determined whether the traditional knowledge of elephant care in such cultures is viable and sustainable in the context of Western notions of 'welfare' and 'wellness' (Laine)."

As we acknowledge in our target article, the history of the interspecies relationships through which the Karen mahouts have come to know elephants has not been benign. But the history of interspecies relationships that have emerged through Western-centric sciences, technologies, economies, and cultures has not been benign either. To be clear, we are not advocating an uncritical, romanticized generalization of "traditional mahout practices" (or any cultural practices). Rather, we argue that we need Karen mahouts and elephants as collaborators in their "entangled" (Barad 2007) futures (cf. Treves). Scientific practice must learn to engage with the self-determination of all community members human and non-human. Many commentators laud the idea of cross-cultural (and perhaps 
cross-species) collaboration, but there needs to be more critical and reflective engagement with how collaboration can succeed in practice.

We do not regard collaboration as just "analyzing [mahout] practices and tempering them according to scientific advances in the behavioral sciences" (Merkham \& Fas); and we certainly do not dismiss ethical concerns about elephant suffering as incompatible with an amalgamated "local" perspective (Suter). We lean toward de la Cadena's (2010) view of collaboration as a "cosmopolitical project" grounded in dialogue across multiple forms and sources of knowledge and experience. Helen Verran, in her work on environmental scientists and aboriginal communities in Australia, suggests that cross-cultural collaboration means "learning to refuse the step which requires a colonising reduction to a shared category, and acceptance that we may not be metaphysically committed to a common world." We are instead capable of "doing difference generatively and in good faith" (Verran 2013, 144). Collaboration calls for understanding as well as compromise and can lead to an outcome that is compatible with the ethics of all the parties (human and non-human) involved. Identifying and achieving shared goals in a mixed community is more likely and sustainable if differences are not denied or obscured.

This collaborative approach requires a deeper engagement with the historical processes underlying present-day conservation issues. It can situate the different perspectives of the communities involved (Haraway 1988) and clarify how mutually satisfactory outcomes can be reached (Barad 2009). This sort of dynamic is evident in the diverse conclusions of our commentators about the situation of elephants in Thailand. Suter, for example, naturalizes elephants as workers within "an industry that is here to stay": "The [elephant] camp isn't the problem, it's the level of welfare at the camp" and "the decline in individual mahout skills." In contrast, Lorimer \& Rahmat approach elephant tourism from a Marxist labor analysis, calling into question the processes that naturalize elephants as workers; they accordingly see the need for a more radical restructuring of human-elephant relations.

Elephant tourism represents a particular extractive labor relationship in only the last 30 or so years out of a 4000-year history of mahout-elephant relations. We could ask whether the elephant tourism is indeed "here to stay" -- and who benefits and loses from the perceived inevitability of elephant tourism? If we extend the temporal frame, we see that, along with indigenous and Thai mahouts, many other actors and interests (including US and Western European ones) have played a role in shaping the current political and economic status of elephants (Hewison 1996; Klima 2002).

In rewilding efforts collaboration alone cannot overcome the many challenges to elephant protection and conservation, such as deforestation, economic pressure, and the instrumentalization of elephants in the current tourist system. However, collaboration can engender relationships of mutual support and trust that are more resilient to social, environmental, political, and economic challenges. This requires more investment of time and energy, as well as more innovative funding models compared to the conservation interventions that bring fly-in, fly-out research and non-local development teams. As Humphreys notes: "In our era of environmental crisis, the interests of humans and elephants cannot be met if they are pitted against one another. A codependency needs to be recognized." 
3. On anthropocentrism and alterity in conservation. In the advocacy of multispecies justice (Celermajer; Crist; Treves), Crist suggests that "Humanity needs to downsize economically and demographically to fit in a diverse world in which all beings can have sovereignty and live out their individual and species destinies (Rees 2020)." This assertion has merit, but it masks important complexities in basing species-wide imperatives on culpability for environmental harm. The burdens of conservation and environmental policy are rarely tied to proportionate liability (e.g., social and environmental justice movements vis-à-vis climate disruption; wild animal culling programs vis-à-vis biodiversity preservation). In making generalized statements about human population control, we cannot ignore the history of environmentalism, including public health campaigns, which extend back to notions of racial supremacy and eugenics (see Briggs 2002). These historical facts -- in which we (academics and others with financial, political, or institutional backing) have been implicated -- need to be understood as the neocolonial approaches to conservation practice that got us here and that are still with us (see Chandan 2018).

Along with the differences between Western-centric and non-Western-centric views and practices discussed earlier, the notion of population control is itself anthropocentric (Chapman \& Huffman 2018), with its hierarchical view of who gets to exemplify the anthropos. This leads to the "othering" of certain human and nonhuman communities, forcing them to shoulder disproportionate burdens.

Multispecies justice (including our approach to rewilding) must avoid simplistic and and culturally biased solutions, such as generalized calls for human and nonhuman population reduction that perpetuate iniquities (Strathern et al., 2019). Crist suggests that "protecting and restoring nature is critical for redefining humanity's relationship with the rest of the world, freeing living beings to express their natural inclinations, co-exist and thrive." Strathern et al. (2019:160) urge that we ask ourselves "which relations are supportive and which are destructive" so as to find a "path toward responsibly facing entanglements that have ubiquitous environmental repercussions". We would suggest examining the relationships in Thailand among elephants (e.g., captive, managed, rewilded, wild) and humans (e.g., mahouts, tourists, scientists), asking specifically when, how and to what degree these relations are supportive or destructive to the collective thriving of members in a mixed community. This must include not just ecological relations, but economic and political relations as well.

4. On labor and human-elephant relationships. We second van der Water et al.'s call to think even further ahead for elephants. Lorimer \& Rahmat ask about the role of labor and capital in our view about care for elephants. They caution against "a model of conservation that would make the future of life conditional on participating in the workforce." The Covid19 pandemic (Wiebers \& Feigin 2020), as van der Water et al. and Treves point out, is laying bare the precariousness of making the care and protection of captive (and free living) wild animals contingent on capitalist economic systems.

In the wake of the 1989 logging ban and the emergence of the elephant tourism industry, Asian elephants have been increasingly monetized in Thailand. Since the early 1990s policymakers and other stakeholders have framed the issue of elephant care in terms of "unemployed elephants". This implied that any solution must be focused on finding new forms of employment, without calling into question the assumption that the relationship between humans and elephants is one based on survival (for elephants) in exchange for 
labor (for human demand). Forced labor in the logging industry was traded for monetized performance in tourism. Although (as Suter points out) there has been some mitigation of the harms done by the tourism industry's rapid, unregulated growth, there has yet to be an authentic attempt to address the dissonance in the notion of the "out-of-work elephant" or the fundamental iniquities inherent to the industry itself.

As the societal impacts of the zoonotic threat to human health and well-being from the Covid-19 pandemic (Wiebers \& Feigin 2020) become apparent they expose also the deepest issues of the elephant tourism industry: We are witnessing a disruption to the system similar to the effects of the 1989 logging ban. With this disruption comes a critical opportunity to radically change human-elephant relations in Thailand, an opportunity missed decades ago. Similar to the aftermath of the logging ban, the effects of the pandemic have stripped away the income of humans who use elephants as a labor workforce. This loss of income has caused a significant number of elephants to endure far worse care than they had previously - many getting little or no exercise and insufficient food and water. There has also been an exacerbation of the other industry-wide welfare issues discussed in our target article and reinforced in the commentaries.

These negative effects, however, are unevenly experienced by captive elephants in Thailand. Although no formal study has yet been done on how well elephants have been buffered from the fallout of the pandemic a key factor appears to be the type of relationship the elephant has with mahouts, and the type of relationship those mahouts have with the forests (Paddock and Suhartino 2020). Many of the mahouts whose homes lie in remote mountain villages surrounded by relatively large tracts of forest, have been able to bring their elephants back to their home villages and return them to the forest where they can freely forage (Sivasomboon and Peck 2020). In contrast, mahouts who work as hired labor in elephant camps have little control over the circumstances of an elephant's care; nor do mahouts who may own their elephants but live in more urban areas without access to forest and who are now faced with the challenge of being able to afford food for their elephant (Hatton 2020). None of these relations exist outside the context of work, but there are key differences to consider for their relative constructive or destructive effects. These have important implications for our model of rescue, rehabilitation, and rewilding.

Lorimer \& Rahmat criticize our framework as just another type of labor exchange, but we suggest that this is a misreading of the context and a simplification of the lived experiences of elephants. Lorimer \& Rahmat rightly warn of "ecological labour," a phrase they use to represent a service an elephant may provide to an ecosystem, such as "dispersing seeds" or "disturbing vegetation". There are cases in which elephants are indeed used to perform ecological labor for the sake of human interests (see Münster 2016). What we are advocating, however, is decidedly not this, despite the fact that our proposed approach to rewilding does remain constrained by the existing legal and economic status of elephants in Thailand. Our hope, however, is that our approach will subvert the existing relationship between labor and care. For example, under the model of ecotourism designed to fund elephant rewilding by Mahouts Elephant Foundation (MEF) in rural northern Thailand, elephants do not engage in labor practices on behalf of mahouts or tourists, nor are they merely providing an ecological service to their environment, let alone one from which they do not benefit.

MEF's rewilding initiatives are subsidized through ecotourism, and mahouts continue to provide care-labor for elephants in the role of forest guides and elephant guardians. 
Tourists must trek out to wherever the elephants are in the forest for the privilege of observing them from a distance. As with ecotourism overall as well as in any field research there are important ethical questions regarding intrusion (even if respectful) into the space of others, as well as the voyeurism inherent in observation. That said, this approach remains an important step away from the status quo of elephant tourism, in part because it decouples the lives and bodies of elephants from notions and expectations of labor. The hope is that this critical shift will reframe human-elephant relations and interdependence, freeing elephants from reliance on tourism or other forms of capitalist economies (van de Water et al.; Humphreys).

5. Conclusion. The scientific evidence has long indicated that elephants are persons (Locke 2017; Wise 2012), who are self-aware (Plotnick et al. 2010) and have needs, desires, culture, life stories and histories of their own. It is also clear that elephants are not a domesticated species (Correia-Caeiro) and thus that elephant sociobiological needs must be understood in the context of their unique evolved capabilities. Given the constraints on habitat availability, current environmental dangers, and the political and economic position of elephants in Thailand, complete severance of the mahout-elephant relationship to meet the conditions that some commentators (e.g., Lee \& Lindsay) consider to be genuine "rewilding" is neither feasible nor does it necessarily offer the best conditions for Thai elephants to thrive in.

The relationship between elephants and mahouts is just one among many: elephants also have relationships with other elephants, with other sentient beings, and with biotic and abiotic parts of their environment. The success of any attempt to make this single relation more supportive depends on adapting these other relations too. Mahouts are severely limited in the type of protection and care they are able to provide to elephants without adequate forest for elephants to live in. NGO members and community leaders cannot facilitate long-term community support if protection and conservation practitioners dismiss indigenous knowledge practices and use a top-down approach to policy. Local government officials cannot implement necessary policy changes that protect elephants and forests when there is intense corporate pressure for deforestation in the service of the meat industry. In addition, elephants who have spent decades in intensive captivity will not have the practical knowledge to adapt and thrive without careful rehabilitation by experienced elephant and human allies.

A framework for multispecies justice (Celermajer) and compassionate conservation offers a way to assess potential in situ protection and conservation efforts. Through this, our model for rescue, rehabilitation and rewilding - derived and achieved as a collaboration provides an opening to a process which must co-evolve, informed by research grounded in the recognition of the many dynamic relations in which elephants and diverse community members are situated.

\section{References}

Baker, L., and Winkler, R. (2020). Asian elephant rescue, rehabilitation and rewilding. Animal Sentience 28(1). 
Barad, K. (2007). Meeting the Universe Half-Way: Quantum Physics and the Entanglement of Matter and Meaning. Durham. Durham and London: Duke University Press.

Blumstein, Daniel T. \& Lynch, Kate E. (2020) Innovative, yes: But is it rewilding? Animal Sentience 28(8)

Briggs L. (2002). Reproducing Empire : Race, Sex, Science, and U.S. Imperialism in Puerto Rico. American Crossroads. Berkeley : University of California Press.

Celermajer, Danielle (2020) Rethinking rewilding through multispecies justice. Animal Sentience 28(12)

Chandran, R. (2018). Myanmar's Indigenous People Fight 'fortress' Conservation. Reuters, August 8, 2018.

Chapman, Colin A. \& Huffman, Michael A. (2018) Why do we want to think humans are different? Animal Sentience 23(1)

Correia-Caeiro, Catia (2020) Rewilding and domestication: Clarifying terminology. Animal Sentience 28(17)

Crist, Eileen (2020) Protecting nature, freeing beings. Animal Sentience 28(13)

De la Cadena, M. (2010). Indigenous Cosmopolitics in the Andes: Conceptual Reflections beyond 'Politics.' Cultural Anthropology 25 (2): 334-70.

Hatton, C. (2020). Coronavirus: Thai elephants face starvation as tourism collapses. BBC News. March 31. https://www.bbc.com/news/world-asia-52110551

Haraway, D. (1988). Situated Knowledges: The Science Question in Feminism and the Privilege of Partial Perspective. Feminist Studies 14 (3): 575.

Hewison, K. (1996). Political Oppositions and Regime Change in Thailand. In G. Rodan (Ed.). Political Oppositions in Industrialising Asia (78). London: Routledge.

Humphreys, Rebekah (2020) Philosophy, ecology and elephant equality. Animal Sentience 28(11)

Kaijser, A. \& Kronsell, A. (2014). Climate Change through the Lens of Intersectionality. Environmental Politics 23 (3): 417-33.

Klima, Alan. (2002). The Funeral Casino: Meditation, Massacre, and Exchange with the Dead in Thailand. Princeton and Oxford: Princeton University Press.

Kopnina, Helen (2020) Of elephants and men. Animal Sentience 28(2)

Lainé, Nicolas (2020) Anthropology and conservation. Animal Sentience 28(5)

Law, J. \& Mol, A. (2002). Complexities: An Introduction in Complexities: Social Studies of Knowledge Practices. Law and Mol (eds). Durham: Duke University Press.

Lee, Phyllis C. \& Lindsay, W. Keith (2020) A "halfway house" for improving captive welfare. Animal Sentience 28(14)

Locke, P. (2017). Elephants as persons, affective apprenticeship, and fieldwork with nonhuman informants in Nepal. HAU: Journal of Ethnographic Theory, 7(1), 353376.

Lorimer, Jamie \& Rahmat, Khatijah (2020) Elephants at work. Animal Sentience 28(7) Massiot, Elodie (2020) Challenging our conception of wildness. Animal Sentience 28(19) McCargo, D. (2001). "Populism and Reformism in Contemporary Thailand." South East Asia Research 9 (1): 89-107. https://doi.org/10.5367/000000001101297333.

McGrew, William C. (2020) Practicalities of re-wilding. Animal Sentience 28(9)

Mehrkam, Lindsay R. \& Fad, Otto (2020) Animal welfare science and "a life worth living" for wild and captive elephants. Animal Sentience 28(10) 
Münster, Ursula. 2016. Working for the Forest: The Ambivalent Intimacies of HumanElephant Collaboration in South Indian Wildlife Conservation. Ethnos 81 (3): 42547.

Paddock, R. \& Suhartono, M. (2020) As Tourism Plummets in Thailand, Elephants are Out of Work, Too. The New York Times

Pauketat, Janet VT (2020) A psychological perspective on elephant rewilding. Animal Sentience 28(4)

Plotnik, J. M., de Waal, F. B., Moore III, D., \& Reiss, D. (2010). Self-recognition in the Asian elephant and future directions for cognitive research with elephants in zoological settings. Zoo Biology, 29(2), 179-191.

Phalke, Sagarika (2020) Rewilding elephants: A solution or a potential problem? Animal Sentience 28(15)

Rees, William (2020) Ecological economics for humanity's plague phase. Ecological Economics 169: 1065) 19.

Sivasomboon, B. \& Grant, P. (2020) With No Tourists, Thai Elephants Return to Natural Habitats. The Associated Press.

Snijders, Lysanne (2020) Ecological and evolutionary dynamics of elephant rewilding. Animal Sentience 28(6)

Stengers, I. (2005). The Cosmopolitical Proposal. in B. Latour, \& P. Weibel (Eds.) Making Things Public: Atmospheres of Democracy, (pg. 994-1005). Boston: MIT Press.

Strathern, M., Sasser J.S., Clarke, A., Benjamin, R., Murphy M., Haraway, D., Huang, Y., \& Wu, C. (2019). Forum on Making Kin Not Population: Reconceiving Generations. Feminist Studies 45 (1): 159-72.

Suter, Ingrid (2020) Rewilding or reviewing: Conservation and the elephant-based tourism industry. Animal Sentience 28(3)

Treves, Adrian (2020) Elephants and pandemics. Animal Sentience 28(20)

van de Water, Antoinette; Henley, Michelle; Bates, Lucy; \& Slotow, Rob (2020) Future of Thailand's captive elephants. Animal Sentience 28(18)

Verran, H. (2013). Engagements between disparate knowledge traditions: Toward doing difference generatively and in good faith. In L. Green (Ed). Contested ecologies: Dialogues in the South on Nature and knowledge, (pg. 141-161). Capetown South Africa: University of CapeTown Press.

Wallach, Arian D.; Jasinghe, Sujeewa; Fernando, Sudarshani; and Rizzolo, Jessica Bell (2020) Compassionate conservation and elephant personhood. Animal Sentience 28(16)

Wiebers, David \& Feigin, Valery (2020) What the COVID-19 crisis is telling humanity. Animal Sentience 30(1)

Wise, S. M. (2012). Nonhuman rights to personhood. Pace Environmental Law Review 30 (3): 1278-1290 